\title{
La reproducción humana asistida en el ordenamiento jurídico español: análisis de cuestiones de especial relevancia
}

\author{
Assisted human reproduction: the problems that arise from bioethics and public \\ law
}

\author{
Juan Francisco Rodríguez Ayuso ${ }^{1}$ \\ Universidad International de La Rioja, España
}

\begin{abstract}
RESUMEN El objetivo del presente trabajo consiste en ofrecer un análisis sistemático de las novedades que traen consigo los avances propiciados por las Nuevas Tecnologías de la Información y de la Comunicación (TIC) en el ámbito de los Derechos Humanos y, de forma muy especial, en la reproducción humana asistida. En este punto, se exponen las principales controversias de índole moral y legal, así como la necesaria interrelación que ambas han de presentar para conseguir definir un modelo permanente de progreso y desarrollo. Para alcanzar esta finalidad, se parte de un estudio inicial del paradigma so-cial actual, propiciado por el desarrollo de las Nuevas Tecnologías, pasando por una aproximación teórica a los Derechos Humanos implicados y a la disección, protección jurídica y garantía de estas técnicas.
\end{abstract}

PALABRAS CLAVE Derechos humanos; reproducción humana asistida; filiación; derecho; bioética.

ABSTRACT The object of this paper is to provide a systematic analysis of the new developments in human rights produced by advances in information and communication technologies, especially in assisted human reproduction. The main moral and legal controversies are set out, as well as the necessary inter-

1. Juan Francisco Rodríguez Ayuso. Profesor Ayudante Doctor de Derecho Administrativo (acreditado por ANECA) y Coordinador Académico del Máster Universitario en Protección de Datos en la Universidad Internacional de La Rioja (UNIR). E-mail: juanfrancisco.rodriguez@unir.net. ORCID iD: https://orcid.org/0000-0003-4721-1465. 
relationship that these must present in order to establish a stable model of progress and development. To achieve this purpose, the starting point is an initial study of the current social paradigm, fostered by the de-velopment of new technologies; the article then presents a theoretical approach to the human rights involved, in order to study the dissection, legal protection and guarantee of these techniques.

KEYWORDS Human rights; assisted human reproduction; filiation, law; bioethics.

\section{Introducción}

La sistemática y constante evolución de la ciencia comporta un permanente reto para la Bioética y el Derecho, así como para sus implicaciones sobre los Derechos Humanos, como el derecho que tiene todo individuo a la vida, la libertad y la seguridad, el derecho al bienestar y a la asistencia médica, la igualdad ante la ley o el derecho a la libertad personal. Ello obliga a que los Estados no permanezcan impasibles ante esta evolución y ante los nuevos desafíos que la sociedad demanda.

La dificultad reside en que los progresos científicos generalmente inciden sobre lo más profundo de la naturaleza humana y conllevan una permanente revisión del influjo que comportan en el valor de la vida, la dignidad o integridad de la persona.

Una de las figuras que más ha evolucionado en los últimos años y que más interés ha despertado en la población es la reproducción humana asistida. Habitualmente, cuando se habla de reproducción asistida se hace mención, tanto a la inseminación artificial (homóloga -con semen de la pareja- y heteróloga -con semen de donante-), como a la fecundación in vitro y sus diversas modalidades. Sus métodos ofrecen una suerte de atribución de la paternidad biológica a determinadas personas que, sin esta alternativa biotecnológica, no hubieran podido tener descendencia. Estos sistemas adquieren pre-eminencia en aquellos casos en que el ordenamiento jurídico de los Estados desea dotar de cierta normalidad determinados compromisos adquiridos en materia de bioética y nuevas tecnologías que fuerzan a valorar, desde una nueva óptica, múltiples controversias que se tenían por solucionadas de un modo tradicional; a ello se añaden los incuestionables beneficios que esta regulación aporta al combatir numerosas arbitrariedades e ilegalidades que su alegalidad trae consigo. El dilema de los vínculos entre la ley y la moral (constantemente presente en este campo), reaparece y se revitaliza cuando se demanda que sea el Derecho quien establezca un vínculo plausible entre ambos estadios.

En este sentido, podemos aseverar que el modelo familiar actual es muy diverso, de tal forma que tienen cabida en el concepto de familia todos aquellos grupos o particulares que conforman un epicentro de coexistencia, al margen de la metodología 
usada para conformarla y del sexo de sus miembros, en tanto que sean respetadas las reglas jurídico-éticas predeterminadas y establecidas. La consideración clásica de familia, cuyo origen se establece en el pensamiento romano y cuyas bases venían constituidas por la unión matrimonial heterosexual y por la perpetuación natural de la especie, adquiriendo un papel relevante las figuras de la madre y del padre en cuanto progenitores, dejan conceptualmente espacio a nuevos prototipos de familia, ahora conformados también por otro tipo de relaciones de naturaleza homosexual, monoparental o, incluso, a uniones de hecho o de Derecho. Debido a estos motivos, nuestro más alto Tribunal ${ }^{2}$ reiteradamente se ha pronunciado aceptando un modelo múltiple de familia, que sobresale en los últimos tiempos merced a la contribución de los progresos de naturaleza sociológica, legislativa o científica, entre los que se encuentran los originados dentro del ámbito de las técnicas de reproducción asistidas, haciendo posible que, tanto individuos con problemas físicos de infertilidad como parejas homosexuales o, inclusive, mujeres a título individual, puedan tener descendencia con plenos efectos legales.

Estos métodos de reproducción se encuentran reglamentados en la Ley 14/2006, de 26 de mayo, sobre técnicas de reproducción humana asistida ${ }^{3}$ (en adelante, LTRHA) y han sido significativamente criticadas, tanto desde posiciones morales como también jurídicas. Dentro del ámbito jurídico, la reglamentación que de la filiación originada por el uso de estas prácticas realiza la precitada Ley ha recibido numerosas críticas, amparándose en que los fundamentos en que se sustenta la filiación y las reglas en las que se asienta dentro de nuestro Código civil ${ }^{4}$ tras la modificación efectuada como consecuencia de la Ley 11/1981, de modificación del Código Civil (en adelante, $\mathrm{CC}$ ) en materia de filiación, patria potestad y régimen económico del matrimonio, son distintos y, en opinión de algunos autores ${ }^{5}$, imposible de conciliar: en la filiación mediante técnicas de reproducción asistida podemos ver que se otorga preeminencia a la intención del consentidor de intervenir como progenitor, disponiendo, para sí, este derecho, ya que el mencionado $\mathrm{CC}$ hace prevalecer la realidad del aspecto biológico y la normativa se en-camina a armonizar o a buscar la identificación de los progenitores legales con aquellos que lo son desde una perspectiva biológica.

2. Sentencia del Tribunal Constitucional (en adelante, STC -Pleno-) 116, de 17 de junio (1999).

3. Boletín Oficial del Estado (en adelante, BOE) núm. 126, de 27 de mayo de 2006.

4. Real Decreto de 24 de julio de 1889 por el que se publica el Código Civil. BOE núm. 206, de 25 de julio de 1889.

5. LEMMENS y FLAVELLE (2017) p. 78. 


\section{Importancia del Bioderecho}

Todas las controversias de índole moral que surgen a raíz de los avances en el campo biomédico (ciertamente relacionadas con Derechos Humanos fundamentales tan importantes como los de igualdad ante la ley, libertad religiosa, ideológica y de conciencia o derecho a la vida), presentan una gran relevancia desde el ámbito de la bioética y también tienen un alcance legal evidente o, lo que es lo mismo, una relevancia desde el punto de vista del Bioderecho ${ }^{6}$. En este sentido, la manipulación genética, el ámbito eugenésico del embrión, la configuración de los futuros seres humanos en estado de gestación, la configuración previa del ámbito genético de aspectos del ser humano o el empleo de los datos resultantes, son únicamente parte de las prácticas posibilitadas por el aumento de las técnicas biomédicas.

La importancia colectiva de los efectos y connotaciones legales de la investigación biomédica resulta fuera de toda duda, toda vez que esta relevancia tiene su origen en complejas relaciones multisectoriales en las que intervienen, además de lo científico y lo bioético, lo jurídico y la formación global. Además, también subsiste una estrecha vinculación dentro los temas biojurídicos y, dentro del Derecho, los Derechos Humanos; visto esto, podemos plantearnos cómo debería entenderse la autonomía de los sujetos de experimentación en relación con el desarrollo biomédico, cómo debería ser regulada la obtención, el almacenamiento, el empleo y el comercio de análisis biológicos o cuál conlleva mayor interés legal: la vertiente íntegra del ser humano o la prosperidad social, además de tener que determinar cuál tiene mayor relevancia: la opción de escoger o la salvaguarda absoluta del aspecto vital ${ }^{7}$. En consecuencia, podemos afirmar que todas estas interrelaciones ponen de relieve categorías jurídicas esenciales que no se refieren únicamente a aspectos que tienen que ver con la biomedicina y su interrelación con lo jurídico, tanto más, repetimos, con los derechos del hombre, como la dignidad, la libertad, la moralidad, la justicia o la ecuanimidad.

Fruto de todo ello, deviene imprescindible proceder a la identificación y definición de un nuevo encuadre legal vinculante con el objetivo de decretar, reglar, sentenciar y sancionar supuestos legalmente controvertidos en el ámbito específico de la biomedicina. Esta necesidad resulta aún más patente si tenemos en cuenta algunos hechos objetivos que ponen de manifiesto la falta de eficacia del Derecho positivo tradicional para resolver determinadas cuestiones de naturaleza jurídica hasta ahora desconocidas, resultantes de las probabilidades descubiertas por el progreso de la biomedicina, como son los siguientes:

6. ALBERT (2018) p. 224.

7. APARISI (2019) pp. 213-214. 
En primer lugar, existen posiciones jurídicas ciertamente diferenciadas en relación con estas cuestiones, lo que obstaculiza e impide un diálogo eficaz y enriquecedor que permita avanzar en dirección a un acuerdo.

En segundo lugar, el ámbito jurídico de lo hermenéutico no resulta suficiente de cara a analizar aquellos supuestos más complejos, dado que la apreciación de aquellos casos y los resultados y efectos es relativa (circunstancial a vocaciones, doctrinas, valores y prioridades concretas), además de que los magistrados, en multitud de ocasiones, ponen de manifiesto su desconocimiento sobre asuntos de esta naturaleza.

En tercer lugar, destaca la existencia de amplios vacíos legales, ya que las leyes y reglamentación con relación a estas cuestiones no es completa, antes al contrario.

En cuarto lugar, en general, los actuales ordenamientos jurídicos no abordan de manera suficiente la regulación biomédica, denotando su insuficiencia para poner remedio a los conflictos biolegales de modo vinculante.

En quinto lugar, es patente la inexistencia de políticas públicas sobre biomedicina, originado por la falta de leyes competentes.

En sexto lugar, de igual modo, es prácticamente inexistente la normativa en relación con aspectos relativos a cómo regir los ejercicios biomédicos y a aquellas técnicas clínicas de naturaleza complicada que comportan la ejecución de métodos extraordinarios. Además, las leyes vigentes son, en general, anacrónicas, prescritas y discordantes.

En séptimo y último lugar, los principios de ética biomédica, por los que habitualmente se estudian y departen estas cuestiones, no suelen ser jurídicamente vinculantes.

Todo lo anteriormente descrito pone de relieve las inconsistencias de nuestros ordenamientos jurídicos para abordar suficientemente diversas cuestiones relacionadas con las prácticas biomédicas ${ }^{8}$.

Los primeros indicios del Bioderecho aparecen en Europa, allá por los años ochenta, y surgen en el entorno de las labores del Consejo Europeo, con sus influencias y congresos, completándose con la Convención comunitaria sobre los derechos del hombre, las sentencias de la Corte comunitaria y, en general, el sistema jurídico europeo. Todas las instituciones anteriores son imprecisas al referirse al Bioderecho, pero si son consecuentes con la necesidad de crear un marco jurídico concreto, que aparezca por encima del aspecto jurídico positivo clásico, de cara a normalizar las actuaciones cotidianas provenientes del mundo biomédico originadas por la evolución de lo científico y lo tecnológico y con impacto en relevantes Derechos Humanos y fundamentales, como, en lo que aquí interesa, el derecho a la vida o el derecho a la libertad en sus múltiples manifestaciones.

8. ROMEO (2017) p. 21. 
La justificación de este requisito ha sido que la actividad del sistema jurídico comunitario y la integración de facultades esenciales en el entorno institucional comunitario ya no asumían un análisis del todo apropiado de los Derechos Humanos. Por ello, y según parece, esta cuestión fue objeto de inclusión en la agenda por argumentos sujetos a la bioética, la cual, en ese momento, experimentaba un desarrollo evidente en Europa. El Derecho determinó la presencia de organismos que aceptaron el enfrentamiento de la interconexión del mundo científico y del tecnológico con resoluciones referentes a la constitución que, al mismo tiempo, posibilitaban un análisis y evaluación con un mayor grado de exactitud de las reglas 9 . La acción fue interpretada con un sentido de sensatez política de lo jurídico, que contó con el respaldo de los comités del mundo bioético, las sentencias emitidas y aquellas decisiones de los parlamentos de los territorios comprometidos. Hacemos mención escueta a ellas:

Si nos remontamos a primeros de los años ochenta, el Consejo europeo y, a primeros de la década siguiente, la Comunidad Europea, ya disponían de un Comité focalizado en el ámbito biomédico: de un lado, el Comité Director para la Bioética, y, de otro, el Grupo de Consejeros para la Ética de las Ciencias y las Nuevas Tecnologías. Ambas instituciones se encontraban formadas por expertos en diversas disciplinas, originarios de los países comunitarios, que procedieron a la elaboración, unificadamente, de los documentos (no vinculantes) en relación con múltiples casos donde no era necesaria su aportación.

Atendiendo a una severa disciplina, el Comité procedía a emitir juicios de valor, ya que realizaba sugerencias que, si procedía, resultaban posteriormente aprobadas por el grupo ministerial. La importancia de estas resoluciones tiene su justificación en la pre-sentación de conceptos contundentes y la exposición pormenorizada de causas, los que eran publicados como anexos que acompañaban al contenido de la recomendación. En consecuencia, el esfuerzo en este campo residió en definir principios legales y morales que permitieran una regulación de la ejecución de las herramientas proporcionadas por el mundo biomédico.

$\mathrm{Al}$ respecto, el planeamiento resultaba parecido al de las sentencias clásicas, si bien teniendo en cuenta que el trabajo de la jurisprudencia resultaba delimitado a la resolución de casos concretos. Al contrario de las atribuciones ordinarias del Consejo europeo en relación con aquellos derechos reconocidos al individuo, las sentencias provenientes del ámbito comunitario eran más profusas.

De tales sentencias podemos extraer una consecuencia determinante: en la década de los 6o, este órgano había protagonizado una importancia primordial a la hora de in-sistir en que la obediencia y el acatamiento de los derechos fundamentales era un capítulo inclusivo aquellos aspectos tradicionales del mundo jurídico, en los que este

\footnotetext{
9. CASADO (2018) pp. 175-176.
} 
órgano aseguró su acatamiento. De otro lado, la evolución de los acuerdos internacionales fortalecía, quizá menos la atribución de competencias, como el reconocimiento de la facultad de la Unión Europea para llevar a cabo determinadas actuaciones y lograr resultados concernientes a las facultades legales esenciales y aspectos provenientes de la Bioética.

Partiendo de esta afirmación, se favorecieron, en la década de los años ochenta, una serie de manifestaciones en relación con la posibilidad de obtener un conjunto patrimonial que, proveniente de la genética, no fuera objeto de manipulación, actuación que dispondría el origen del precitado Comité. De igual modo, los acuerdos que la Unión Europea adoptó a mediados de la década de los años ochenta aglutinaron un compendio teórico relevante desde una perspectiva jurídica en el entorno científico relativo a la existencia del ser humano ${ }^{10}$.

Después del acuerdo, el núcleo jurídico más relevante concerniente al ser humano comenzó a tener el valor relevante merecido dentro de los sistemas legales comunitarios y en el ámbito jurídico europeo globalmente considerado. Ello devino en una aparición del mundo jurídico científico, que originó, si bien de una forma aún ambigua, un bloque legal de instrucciones sobre esta cuestión.

Pudimos constatar, incluso, la notable similitud existente atendiendo a principios básicos, asumidos por el Consejo de Europa, y aquellos otros señalados a nivel comunitario, apoyándose mediante sugerencias emitidas por los consejeros, en determinadas normativas legales en el texto que recoge aquellos aspectos más relevantes de los derechos inherentes al ser humano, que disponía la necesidad de aplicar los aspectos jurídicos biomédicos y biotecnológicos.

De igual modo, fue formado un bloque normativo basado en principios elementales y en derechos humanos fundamentales, de entre los cuales se encuentra la necesidad de respetar la dignidad del ser humano, su independencia, la no marginalidad, la salvaguarda de respeto hacia su integridad física, la protección específica de los seres humanos más débiles e indefensos, la necesidad de respetar su intimidad y de reconocer el papel que han de ejercer los órganos éticos más relevantes. Amén de lo anterior, el sistema jurídico europeo concretó aún más la práctica desarrollada por algunos elementos esenciales, de entre los cuales se incluye la necesidad de respetar la intimidad de los individuos y el reconocimiento de que todos son iguales; ello propició, en resumen, la aparición de nuevas reglas, como el respeto por la dignidad, resultado de aminorar las consecuencias de otras tesis comunitarias (especialmente en materia económica), enfatizándolos en la relación del individuo con el mundo biomédico.

10. VALDÉS (2019) p. 1198. 
Tal contexto determinó que se afirmara que los aspectos más esenciales del ser humano no afectaban exclusivamente a las personas, por su función operacional económica o social, sino también, y muy específicamente, por su calidad de seres humanos. Se determinó, por ende, la imposibilidad de que la puesta en funcionamiento de los derechos fundamentales se restringiera al círculo del ámbito jurídico europeo, de modo que esos derechos lograban el nivel de reglas originarias del mundo comunitario, colaborando en la finalidad básica de configurar tales derechos como una aportación fundamental de cara a la novedosa creación europea, así como la formación de una ciudadanía comunitaria.

Podemos concretar, por tanto, que el nuevo Derecho que aparece (el incipiente Bioderecho) fue una piedra de toque clave para el desarrollo de una nueva base política europea, pues, se puede advertir de las labores de quienes aconsejan al respecto, la actual realidad europea supuso el arranque que posibilitó ampliar el ámbito de actuación de la, por entonces, rama filosófica de los derechos de la persona, adaptado a las ciencias de la vida, que dilató su dimensión, aportando nuevas figuras y derechos.

La ampliación, extensión y desarrollo de los Derechos Humanos acarreó el abandono de un entorno reducido que consideraba al individuo como sujeto político, ya que el progreso biomédico, con su dimensión de intervención y modificación genética situaban la magnitud corporal de las personas en el ámbito de los Derechos Humanos. Esta supuso una inicial dificultad para definir la dimensión de una nueva doctrina, ya que la ambigüedad corpórea era prácticamente infranqueable; tal es así que, del mismo modo que el ámbito biológico concibe a la persona como una mezcla de lo físico y lo moral, para el mundo jurídico tradicional será un ser dotado de determinados atributos y reconocimientos.

En consecuencia, en la actualidad, el ser humano se sitúa en el foco de la doctrina instaurada y, además, la persona se propalaba en su dimensión más amplia. Al hacer referencia a este tema, bastantes de los preceptos emanados por la Convención aludían a los distintos episodios de evolución biológica anteriores al surgimiento, entre ellos, el precepto catorce, referido a la ausencia de determinación de si es hombre o mujer; el siguiente precepto, relativo al estudio científico con personas, o el precepto decimoctavo, centrado en analizar muy concretamente el estudio embrionario.

No obstante, al igual que en el apartado concreto, este órgano ratificó la diferencia típica de los distintos seres humanos en cuanto individuos intrínsecos de derechos, al igual que varias situaciones biológicas que hacían posible, en exclusiva, ostentar una adecuada garantía jurídica, los aspectos menos claros en relación con este asunto permanecieron.

De otro lado, la Convención propició una especie de subsistencia de responsabilidad legal única: la ampliación de la garantía, en algunos puntos, en relación con sucesiones venideras. El concepto que se impuso al respecto se concretó en que de- 
terminados daños de la integridad de la persona, así como los problemas que estos implicaban, tenían la posibilidad de suponer efectos irremediables en relación con los frutos obtenidos. Esta genética, por tanto, tomaba un protagonismo en los trabajos de la Convención y se erguía con fuerza en el debate. El desarrollo que se llevaba a cabo en esta ejecución de los derechos del hombre aparecía como una auténtica novedad, toda vez que la persona no resultaba desprotegida exclusivamente en su misma configuración, tanto más fruto del nexo que lo ligaba a otras personas, como eran las propiedades de lo genético. Dicha afirmación se presentaba como un hilo articulador del nuevo instrumento.

Por una parte, la tarea de la Convención se configuró como el trampolín desde el que, años más tarde, se identificarían los preámbulos del Bioderecho. De otro lado, la ampliación de los beneficiados por los derechos trajo consigo también una gran variedad de posibles incumplidores. La divulgación de la voluntad del legislador europeo permitió ver un problema adicional en esta propuesta sobre los Derechos Humanos: las agresiones contra la identidad de la persona podían repetirse y aumentar ante una incorrecta utilización de las técnicas provenientes del ámbito biomédico. Tanto más, la problemática derivada de la infracción de los derechos inherentes al hombre, aparte de implicar al titular de los derechos, abría la puerta a nuevos estratos o estamentos, por ejemplo, al Estado. El Estado, por propia naturaleza, emergía como responsable del orden de estos intervinientes y su papel en el sistema, atendiendo a que todos estos podían interferir directamente en la parte corporal por medio de actuaciones que eran cometidas. Estas actuaciones del mundo biomédico podían, pues, establecer la responsabilidad colateral del aparato estatal en cuanto culpable en relación con aquellos posibles efectos dañinos que, como consecuencia de una actuación activa o pasiva a la hora de controlar a aquellos que infrinjan los derechos inherentes a la persona, eran susceptibles de provocar a los miembros.

Finalmente, el trabajo específico del espacio comunitario básicamente se centró en producir replicas determinadas de cara a disciplinar diversas prácticas provenientes, de una forma global, del mundo biomédico y genético, ya que estas eran objeto de desarrollo. De este modo, el Consejo europeo reglamentó, verbigracia, el régimen legal de los bienes provenientes de la sangre y posibilitó que determinadas partes del ser humano pudieran circular e ir destinadas a realizar operaciones de trasplante.

Sin embargo, resulta difícil adoptar una política europea que aportara un derecho común con los nuevos retos de los avances biomédicos sin un cuadro legal extensivo y que admitiera el avance en una legislación comunitaria. Máxime aún, ante la carencia de un consenso notable, moral, político o ideológico sobre asuntos tan delicados que contenían, además de connotaciones jurídicas, otras de tipo social y antropológico.

En ese escenario, la Comunidad Europea se fijó como objetivo la elaboración y determinación de preceptos que consagraran determinados fundamentos constitutivos 
del Bioderecho, asumido como un Derecho emblema que estableciera limitaciones a lo científico y a lo tecnológico, contribuyendo, simultáneamente, a precisar una identificación sólida del ser humano.

\section{Reproducción humana asistida: perspectiva jurídico-ética}

Tras el surgimiento en Reino Unido, a finales de la década de los setenta, del primer menor concebido por medio de técnicas fecundadoras in vitro, en la actualidad, son muchos los casos de personas nacidas como resultado del empleo de estos y otros instrumentos a lo largo y ancho del planeta. En nuestro país, tuvimos que aguardar algún tiempo, concretamente hasta mediados de la década de los años ochenta, donde tuvo lugar el nacimiento del primer niño cuya concepción se produjo por medio de estas técnicas. Teniendo en cuenta que, tradicionalmente, lo jurídico no tiene capacidad de res-puesta simultánea a los progresos de la ciencia, hubo que esperar cuatro años a que se decretase en España la Ley 35/1988, de 22 de noviembre, sobre Técnicas de Reproducción Asistida ${ }^{11}$, que, es justo reconocer, fue de las pioneras en promulgarse en el ámbito de la Unión Europea.

El propósito de esta norma legal no era otro que aceptar el uso de las prácticas de reproducción asistida ante situaciones de infertilidad o para prevenir y tratar problemas cuya razón de ser residía en aspectos genéticos o hereditarios (artículo 1); sin embargo, estos no eran los únicos fines perseguidos, ya que la norma también posibilitaba, en su artículo 6.1, que las mujeres, a título individual, pudieran acceder a estas prácticas, al significar que "toda mujer podrá ser receptora o usuaria de las técnicas reguladas en la presente ley". A la vista de lo anterior, podemos deducir, además, que podrían ejercerlas sin aducir problemas de infertilidad, sino exclusivamente con el fin de atender sus necesidades maternales.

Además, la norma, en su artículo 5, protegía la privacidad del donante que ofrecía sus células sexuales al benefactor de tales prácticas, permitiendo su exploración y experimentación tanto con gametos como con preembriones. En lo que aquí respecta, reglamentaba, en sus artículos 7 a 10, la identidad de los neonatos a través de estas técnicas de reproducción.

Estos y otros puntos de la Ley, que introducía en su clausulado elementos administrativos, penales y civiles, fue objeto de un recurso de inconstitucionalidad que se sustentó en tres razones fundamentales: ser contraria a las reglas constitucionales que marcaban las características que debía reunir la conformación de la estructura familiar; infringir el artículo 15 de la Constitución Española (en adelante, CE) ${ }^{12}$ al no

11. BOE núm. 282, de 24 de noviembre de 1988.

12. BOE núm. 311, de 29 de diciembre de 1978. 
aportar claridad en cuanto al nivel legal de estos embriones en fase previa y no satisfacer, por ende, la obligación con la que cuentan los órganos del Estado a la hora de determinar una normativa jurídica en garantía de la vida, y quebrantar el artículo 81.1 CE por influir en la evolución de aquellos derechos inmanentes al ser humano sin tener naturaleza orgánica. Por estos motivos, solicitaban el reconocimiento de la inconstitucionalidad de la ley en toda su integridad o, alternativa y accesoriamente, de aquellos mandamientos concretos que se reflejaban en las alegaciones interpuestas. Empero, esta cuestión fue definitivamente solventada mediante la STC 116/1999, que manifestó su conformidad con la norma constitucional.

Posteriormente, esta norma fue modificada en determinados aspectos mediante la Ley 45/2003, de 21 de noviembre, por la que se modifica la Ley 35/1988, de 22 de noviembre, sobre Técnicas de Reproducción Asistida ${ }^{13}$. Sin embargo, ambas fueron derogadas mediante la actual LTRHA, la cual, en la comparativa jurídica a nivel comunitario, constituye un gran exponente ${ }^{14}$.

La LTRHA no modifica sustancialmente las propuestas contenidas en la anterior regulación, si bien sí que incorpora novedades relevantes: delimitación de la denominación de preembrión, que la circunscribe a su propio ámbito de aplicación; prohibición de la clonación en seres humanos que busquen funciones reproductivas; regulación de novedosas técnicas reproductoras asistidas; ampliación del campo de acción al diagnóstico genético preimplantacional que posibilita nuevos caminos en la prevención de enfermedades de carácter hereditario; fortalecimiento de las anotaciones y otros procedimientos informativos que contribuyan a un más amplio asesoramiento a los usuarios que acudan a esta clase de prácticas, o supresión de las disparidades en lo referente al futuro de los embriones en fase previa que estuvieran crioconservados, además de eliminar las limitaciones que se habían instaurado en la regulación anterior para la generación de ovocitos.

De este modo, la configuración inicial de los artículos 7 a 10 LTRHA, reguladores de la identidad de quienes nacen por medio de procedimientos reproductivos asistidos, en la práctica no aportaban cambios relevantes respecto de la precedente. No obstante, la nueva redacción proporcionada por la Ley Orgánica 3/2007, de 22 de marzo, para la igualdad efectiva de mujeres y hombres ${ }^{15}$, normalizadora de la rectificación registral de la mención relativa al sexo de las personas, agregó la posibilidad de que el marido de la mujer beneficiaria de dichos procedimientos reproductivos asistidos pudiera determinar para sí la identidad del menor que nacía en el caso de que manifestara su aprobación frente a la persona encargada del Registro Civil con anterioridad al alumbramiento. Dicho punto sufrió, después, una alteración merced a

13. BOE núm. 280, de 22 de noviembre de 2003.

14. LLEDÓ (2017) pp. 33-34.

15. BOE núm. 71, de 23 de marzo de 2007. 
la Ley 19/2015, de 13 de julio, de medidas de reforma administrativa en el ámbito de la Administración de Justicia y del Registro Civil ${ }^{16}$, eliminando la obligatoriedad de que la autorización para determinar la identidad hubiera de llevarse a cabo previamente al momento de nacer.

Así las cosas, ni la actual LTRHA ni la precedente han cambiado el sistema de filiación incluido en el Código civil ni se ha agregado observación alguna sobre la filiación procedente de la reproducción asistida. Dicho lo cual, el artículo 7.1 LTRHA establece que la identidad de quienes nacieran utilizando dichas prácticas se continuará determinando mediante las normas contenidas en el compendio básico de artículos civiles (así como por aquellas normas de naturaleza civil que, provenientes de las Comunidades Autónomas, cuentan con una disciplina propia). No obstante, conviene no olvidar que la LTRHA cambia totalmente el sistema de identidad incluido en el mismo, considerando que se basa en la verdad de la biología y, en consecuencia, en el reconocimiento de que el progenitor legal también lo es biológicamente, ya que dentro de la filiación originaria en los procedimientos reproductivos humanos asistidos se otorga predominio a aquella intención del que anhela ejercer como progenitor, dando como resultado que, circunstancialmente, aquel que lo es biológica (el que aporta su material genético) y legalmente (aquellos que asumen el empleo de estos procedimientos en la persona con la que mantienen una relación sentimental o la persona que se disponga para sí la filiación del menor de su pareja) sean diferentes.

Históricamente, la filiación resultante de procedimientos de reproducción humana asistida ha sido considerada como insertas en la filiación natural, al poseer un fundamento biológico, pero la realidad hace ver que las reglas ideadas de cara a la delimitación filiadora natural, que se ven soportadas en la realidad de la biología, no terminan casando por cuanto esta generación no procede de la procreación y la determinación del resultado filial se acuerda voluntariamente, destacando el que deriva del empleo de procedimientos reproductivos asistidos.

No obstante, las prácticas de reproducción asistida se podrán usar por ahora, bien por personas de distinto sexo, se hayan casado o no (por presentar situaciones de infertilidad), bien por personas del mismo sexo o por una persona que quiere ser madre soltera. La utilización de estos medios reproductivos asistidos debe concebirse también, por tanto, como la posibilidad de recurrir a su utilización voluntaria para conseguir descendencia. En este sentido, las discrepancias sobre la posible existencia de esta facultad de procreación, emergen en aquellos casos en que, merced a las innovaciones científicas y tecnológicas, empiezan a usarse métodos reproductivos asistidos; de este modo, el mundo de la ciencia persigue, tras la publicación de la LTRHA, el reconocimiento que concrete el empleo de estos procedimientos reproductivos

16. BOE núm. 167, de 14 de julio de 2015. 
asistidos, asumiéndose que la utilización de estos procedimientos se sustenta en el legítimo deseo de garantizar y cuidar toda forma de salud, en tanto que otros profesionales manifiestan que el empleo de métodos reproductivos asistidos encuentra su justificación en el derecho a la procreación.

Conviene indicar que la CE no incorpora específicamente esta facultad de reproducción. Por esta razón, aquellos que apoyan la existencia de este derecho, lo asumen como una exteriorización de otros derechos que ya están expuestos. Así, parte de la doctrina científica ${ }^{17}$ cree que el derecho a la reproducción puede tener connotaciones constitucionales en la evocación de la libertad personal que la CE hace en el artículo 17.1. Otra parte de ellos ${ }^{18}$, en cambio, asimila esta facultad reproductora a la consistente en constituir un ente familiar, asumido en el marco legal y entendiendo que las reglas referidas a los derechos fundamentales agrupadas en la Norma Suprema deben ser entendidas de acuerdo con el texto que declara universalmente los derechos inherentes al ser humano, texto, este, que, asumido en forma de Declaración Universal, determina que cualquier persona debe contar con la posibilidad de poder formar un núcleo familiar. De igual modo, también se ha puesto en tela de juicio por medio de algún sector doctrinal ${ }^{19}$ el encaje de esta facultad de procreación como subespecie de la facultad que tienen los individuos de disponer con total libertad el número de descendientes, así como el momento de tenerlos (artículo $18 \mathrm{CE}$ ).

Además, ya en el preámbulo de la Ley 35/1988, se observaban indicios que daban carta de libertad a la utilización de los métodos asistidos reproductivos, no ya exclusivamente con una finalidad médica frente a la infertilidad o para tratar dolencias extrañas (a la cual, ciertamente, aludía su precepto primero), sino, de igual modo, cual fórmula para cumplir la mera aspiración de generar descendientes.

Sobre este particular, se puede afirmar que las técnicas de reproducción asistida ya no son un mero remedio a la infertilidad, sino que, además, están al servicio de las aspiraciones de quien anhela generar descendientes y que no padece ningún impedimento médico para llevarlo a cabo. En este sentido, algunos autores ${ }^{20}$ manifiestan que la ley española ya no es un remedio para la infertilidad y prácticamente ha pasado a transformarse en una herramienta de protección y garantía de los derechos de la mujer, de tal forma que constituye un nuevo derecho intrínseco: el derecho de la mujer a la reproducción (sola, casada, homóloga, heteróloga, post-mortem, homosexual, de una madre casada con otra de la que recibe los óvulos o de dos mujeres con semen del mismo donante).

17. ALONSO (2020) pp. 74-77.

18. DÍAZ (2019) pp. 53-131.

19. DANILUK y KOERT (2017) pp. 2045-2412.

20. MARTÍN (2019) pp. 169-179. 
Pero probablemente la contribución doctrinal más relevante en este ámbito sea la que defiende que la facultad procreadora va sobresaliendo dentro del terreno global, aseveración argumentada a través de un estudio de los textos internacionales ${ }^{21}$. En este sentido, esta facultad se centraría en la facultad de crear este núcleo familiar amparado por la Declaración Universal de Derechos Humanos y de la Organización de las Naciones Unidas en relación con la sociedad y con el género, que abarca la facultad humana esencial de elegir libremente y con responsabilidad la cantidad de descendientes, debiendo aludirse igualmente a la determinación de la facultad reproductora, contemplada en el texto de la Organización de las Naciones Unidas sobre eliminación de las formas de marginación frente a las mujeres, la cual, pese a tener una vocación más limitada que la facultad reproductora con fines sanitarios, es una facultad inherente a la persona y con unos márgenes perfectamente descritos.

Por otro lado, es asumible que la dificultad que pudiera entrañar la asimilación de tal facultad al confrontarla con las preferencias de un segundo sujeto de la relación, tendrá que abordarse sopesando las facultades que corresponden a los distintos miembros, no pudiendo entenderse como un derecho categórico.

Por otro lado, también existen opiniones discordantes ${ }^{22}$ que otorgan preeminencia al valor supremo del menor y al hecho de que este venga al mundo con la protección de una figura paterna y otra materna (en este último supuesto, se deduce que el anhelo de la persona a la maternidad por medio de la opción de los métodos reproductivos asistidos pasa a un segundo plano ante la prioridad del menor de contar con una figura materna y otra paterna).

Más allá de lo anterior, y en cuanto al derecho a tener conocimiento de los orígenes familiares, expuestas las incertidumbres doctrinales que existen acerca del derecho o no a la reproducción, debemos mencionar, aunque sea brevemente, otro derecho, como es el que tienen las personas adoptadas, alcanzada la mayoría de edad o durante su minoría a través de sus representantes legales, a conocer los datos sobre sus orígenes biológicos, y que también hace acto de presencia cuando se recurre a la utilización de estos sistemas. Y lo hacen, de forma muy especial, en el supuesto de reproducción asistida heteróloga, en el que los progenitores biológicos no coinciden con los progenitores legales; en este caso, surgen discrepancias sobre si existe o no el derecho de conocer el origen biológico. La implicación del derecho fundamental a la libertad y a la igualdad parece evidente.

Ciertamente, la opinión mayoritaria ${ }^{23}$ se inclina hacia la concurrencia de esta facultad, haciendo prevalecer la dignidad y la intimidad del ser humano contemplada 
dentro de la $\mathrm{CE}$, a lo que se une un mayor progreso y mejora de la personalidad. Incluso, hay opiniones que proponen su elevación a rango de derecho de la personalidad, bien desde el punto de vista de la moralidad (ya que, tras ser conocida la identidad, esta tendrá que decidirse y los progenitores biológicos deberán prestar atención a las necesidades del menor), bien atendiendo a la óptica emocional (que fomenta la normal evolución de la personalidad del hijo, permitiendo que conozca su identidad).

A pesar de ello, la facultad de conocer la procedencia en el supuesto de fecundación asistida con participación de un donante, presenta unas limitaciones preliminares, básicamente debido a la facultad de garantizar la privacidad la persona que dona, la cual desea mantenerse en el anonimato, situación que, de igual modo, se aplica al reconocimiento de la esfera íntima en la vertiente de la persona y de la familia de los progenitores legales del menor. Finalmente, también puede verse restringido porque la identidad ya está decretada en beneficio de los padres legales.

La STC núm. 166/1999 advierte que el anonimato de la persona que dona no presupone una dificultad absoluta para concretar la identificación del menor, ya que el artículo 5 TRLHA atribuye a los menores la facultad de conocer los datos generales que permitan asegurar que se conocen los aspectos de naturaleza genética de su ascendiente, aunque subraya que todas estas cuestiones van encaminadas a mantener la privacidad de la identificación del donante.

\section{Determinación de la filiación}

La relación filial es aquella que se crea en el menor en relación con quienes sean los progenitores. Dicho nexo, que, en principio, tiene una naturaleza biológica y, en consecuencia, es el resultado del acto de procrear, determinando el vínculo legal que existe en la relación paternofilial, ya que, de la misma, dimanan efectos jurídicos desde el momento en el que este nexo aparece. Sin embargo, en diferentes ocasiones la identidad jurídico-biológica no coinciden.

Desde una perspectiva legal, la concreción del vínculo filial hace nacer una serie de consecuencias recogidas en los preceptos 109 a $111 \mathrm{CC}$, como sucede con la identificación del nacido por su apellido, así como la responsabilidad de ambos progenitores de cuidar a los hijos menores y proporcionarles alimento, independientemente de que tengan o no, la patria potestad. Además, la fijación de la identidad igualmente tiene consecuencias en relación con los derechos de sucesión (artículo 807 CC); a la herencia $a b$ intestato, en cuyo caso serán los menores quienes deban optar en primer lugar a la sucesión, o la adquisición de la nacionalidad (artículos 17 y ss. CC).

Por lo que respecta a la fijación de la identidad, conviene analizar diversos supuestos: 


\subsection{Filiación Matrimonial}

\section{a) Homóloga}

La hipótesis menos compleja de cuantas se producen en el uso de los métodos de reproducción humana asistida es aquella que alude a la fecundación dentro del matrimonio y con el consentimiento de ambos progenitores (artículo 6.3 LTRHA), determinando la coincidencia biológica y jurídica. A su vez, esta modalidad presenta dos variantes posibles:

\section{a.1) Inter vivos}

A tenor de la identificación jurídico-biológica, la LTRHA no determina especificidad alguna en relación con la especificación de la identidad, remitiéndose, por ende, al clausulado del CC y, más específicamente, a los artículos 115 a 119. En consecuencia, la maternidad se atribuirá vía nacimiento del niño, mientras que la paternidad lo hará a través de la conjetura expresada en el artículo $116 \mathrm{CC}$, que presume que será padre quien tenga una relación matrimonial con la madre cuando el descendiente haya venido al mundo tras la ejecución matrimonial y con anterioridad a las 300 jornadas ulteriores al momento en que se disuelvan o separen los cónyuges. Esto aparecerá debidamente justificado con la inscripción del nacimiento en el Registro Civil, así como con la del matrimonio de los padres (artículo 115.1 CC).

\section{a.2) Post mortem}

Es esta una hipótesis ciertamente más compleja. En este caso, el artículo 9 LTRHA establece la identidad del menor nacido como consecuencia del uso de las técnicas de reproducción asistida si concurre el fallecimiento de uno de los ascendientes, el padre, que será quien haya donado el semen, en estado de crioconservación, con anterioridad a su defunción.

En este caso, no podrá determinarse legalmente la filiación ni reconocerse efecto o relación jurídica alguna entre el hijo nacido por la aplicación de las técnicas reguladas en esta Ley y el marido fallecido cuando el material reproductor de este no se halle en el útero de la mujer en la fecha de la muerte del varón. No obstante, se dispondrá la filiación del descendiente en favor del esposo muerto si concurren una serie de condiciones:

- Aprobación del marido, que habrá de otorgarse mediante un acto personalísimo (por lo que no puede hacerse mediante representante legal y tiene que ser debidamente reconocida la mujer que va a ser germinada), expreso (no presunto), formal (por medio de escrituras públicas, a través de la figura testamentaria o por instrucciones previas - artículo 9.2 LTRHA-), rescindible (el consentimiento para la aplicación 
de las técnicas en dichas circunstancias podrá ser revocado en cualquier momento anterior a la realización de aquellas).

- Intervalo de un año, a contar tras la defunción y que concluirá en el momento en que la persona sea fecundada con materia reproductiva. Dicho intervalo de tiempo se ha visto incrementado respecto de la normativa precedente, que establecía un intervalo de medio año.

Formalizadas las condiciones anteriores, cabrá la posibilidad de que la esposa del difunto sea fecundada con semen de su esposo, dando lugar al menor.

\section{b) Heteróloga}

Como es sabido, la fecundación heteróloga se produce en aquellos casos en que la persona es fecundada mediante esperma de un donante, ya sea dentro del matrimonio o fuera de él; dentro del primer caso, además, podrá ser en un matrimonio heterosexual u homosexual, que también puede emplear estos procedimientos reproductivos asistidos.

\section{b.1) Matrimonio heterosexual}

La LTRHA contempla expresamente esta modalidad (artículo 8.1).

Dicho precepto, sin embargo, únicamente se limita a establecer que la autorización del esposo en relación con la inseminación de su esposa conllevará que ninguno de ellos pueda rechazar la filiación matrimonial del nacido. Por ello, aun cuando el esposo no es el progenitor natural, el nexo filial se fijará en él, hecho que demuestra la preeminencia del factor volitivo frente al puramente biológico, ya que el donante jamás podrá conseguir la filiación.

En consecuencia, se fijará el nexo filial de la persona descendiente engendrada a través de métodos reproductivos asistidos en beneficio del esposo que proporciona la autorización, considerando la suposición de ser el padre al ampro del artículo 116 CC.

\section{b.2) Matrimonio homosexual}

Tras la modificación experimentada a finales de la primera década del 2000 de la LTRHA merced a la Ley 3/2007, que reguló la modificación en el registro de la alusión a la condición masculina o femenina de los individuos, se patrocina que, en la unión matrimonial entre personas homosexuales sea posible conseguir la identidad del menor.

Esta modificación es el resultado del reconocimiento del nexo matrimonial entre personas del mismo sexo mediante la Ley 13/2005, de 1 de julio, por la que se modifica el Código Civil en materia de derecho a contraer matrimonio ${ }^{24}$, que enmienda el CC 
por lo que respecta a la posibilidad, legalmente reconocida, de este tipo de uniones, haciendo posible la adopción unificada por los sujetos de la pareja o el acogimiento del menor de uno de los miembros por el otro. En este caso, no cabría la hipótesis de nexo filial atendiendo a un doble hecho natural.

Este punto se mantenía vigente hasta la puesta en marcha de la citada reforma, haciendo posible la doble maternidad natural al aceptar que la cónyuge de la mujer que ha tenido el hijo mediante métodos reproductivos asistidos otorgue la aprobación en orden a fijar en su beneficio el nexo filial del nacido.

El supuesto considerado en el artículo 7.3 LTRHA se ha rodeado de diferentes reprobaciones por parte de los expertos ${ }^{25}$, las cuales se han centrado en aspectos como su encaje dentro de la Ley o la hipotética exclusión a que se expone en un doble sentido, ya que la disposición únicamente se aplica en el supuesto de nexo matrimonial entre personas del mismo sexo femenino, de modo que impide, de una parte, esta posibilidad dentro del matrimonio homosexual entre varones, $y$, de otra, que pueda adaptarse a una relación de personas de sexo femenino sin nexo matrimonial, si bien, en dicho supuesto, existe un sector de expertos ${ }^{26}$ que respaldan la imposibilidad de discriminar.

Asimismo, también ha sido objeto de debate su inserción en cuanto modalidad filial natural al aproximarse bastante al supuesto de filiación adoptiva. No obstante, para concretar dicho nexo filial no existe fallo de los Tribunales ni está sujeto al fundamento que atiende a la preferencia del menor; en consecuencia, teniendo en consideración que no existe una tercera modalidad filial diferente de aquella natural, así como la adoptiva, habría de deducirse que el supuesto considerado en el artículo 7.3 LTRHA es un supuesto de filiación natural. Finalmente, en relación con la condición matrimonial o no de esta filiación derivada, debe entenderse que este un requisito sine qua non, puesto que las dos mujeres ejercerán el papel de madres, para lo cual deberán estar necesariamente casadas ya que la disposición no acepta otra opción diferente.

Por lo que respecta a la persona casada con aquella que está gestando, teniendo en consideración el precitado apartado tercero del precepto séptimo de la norma de referencia, cabrá la posibilidad de recibir igualmente la condición materna al dar la autorización, que tendrá que venir precedida de una serie condicionantes:

Atendiendo a cuándo se brinda la autorización, es preciso realizarlo dentro del matrimonio, que no existiera disolución del mismo de ningún tipo y, en cualquier caso, antes de producirse el alumbramiento del menor. No obstante, este último condicionante ha sido anulado mediante la corrección realizada sobre el artículo 7.3 LTRHA por parte de la Ley 19/2015; resultado de dicha modificación, en la actualidad

25. PARDO (2019) pp. 17-20.

26. CRAVIOTTO (2019) pp. 54-89. 
resulta condición optativa el hecho de que la otra persona integrante de la relación otorgue la autorización con anterioridad al alumbramiento del niño, pudiendo hacerlo indistintamente antes o después. Por lo demás, la prestación del consentimiento deberá materializarse mediante una declaración registral, conforme a lo dispuesto en Ley 20/2011, de 21 de julio, del Registro Civil ${ }^{27}$, que, tanto en la actualidad como una vez efectuada la modificación mediante la Ley 19/2015, establece, dentro del apartado quinto del precepto 44, lo siguiente:

“También constará como filiación matrimonial cuando la madre estuviere casada, y no separada legalmente o de hecho, con otra mujer y esta última manifestara que consiente en que se determine a su favor la filiación respecto al hijo nacido de su cónyuge".

Confluyendo estas formalidades, la autorización prestada por la cónyuge de la mu-jer que alumbra traerá como consecuencia y resultado la atribución directa del nexo filial con el menor, apareciendo civilmente en el órgano registral con esta condición materna.

\subsection{No matrimonial}

\section{a) Homóloga}

\section{a.1) Inter vivos}

Caso similar al de la fecundación homóloga en pareja casada, tampoco ofrece mayores problemas el caso de la fecundación que tiene lugar fuera del matrimonio. La LTRHA no aprecia connotaciones concretas para esta hipótesis, debiendo someterse a aquellas normas que, en relación con el nexo filial no derivado del matrimonio, se recogen actualmente en el CC dentro de los artículos 120 a 126.

Así las cosas, la figura paterna tendrá que asistir a aquellos títulos de especificación del nexo filial no derivado del matrimonio contemplados dentro del artículo $120 \mathrm{CC}$, los cuales, básicamente, aluden a la identificación frente al responsable del órgano registral civil, así como la disposición procedente del documento del registro, requisitos que, tras la modificación efectuada merced a la Ley 19/2015, se ven complementados con la declaración correspondiente hecha por la figura paterna dentro del documento legal al llevar a cabo la inscripción de este nacimiento (artículo 120.1 ${ }^{\circ}$ del Código Civil).

Abundando en este asunto, hay que tener presente la relevancia que, tanto el reconocimiento como el expediente registral, puede tener en la autorización prestada para la puesta en práctica de estas técnicas. Así, el consentimiento dado para la rea-

27. BOE núm. 175, de 22 de julio de 2011. 
lización de la inseminación no agrupa los requisitos formales que fija el artículo 120 CC para acometer el reconocimiento, por lo que la expresión de la autorización para dichos métodos reproductivos asistidos no suprime la obligación relativa a que aquel que persiga asumir ser padre preste de nuevo la autorización con el objetivo de decretar de forma extrajudicial dicha identidad.

\section{a.2) Post mortem}

Exactamente igual que en el supuesto de la filiación matrimonial, es igualmente posible el nexo filial no derivado del matrimonio del menor nacido por medio de técnicas fecundadoras una vez producida la muerte. En este caso, es, pues, necesaria la aportación de la conformidad del varón de igual manera y en los mismos plazos, según determina el artículo 9.3 LTRHA. La diferencia, en el momento de disponer la identidad del menor, residirá en que la autorización dada por el varón es tomada como título para comenzar la documentación registral estipulada en el artículo 44.7 de la Ley 20/2011.

\section{b) Heteróloga}

Una mujer, aun sin vínculo matrimonial, se puede acoger exactamente igual a las prácticas de reproducción asistida con colaboración de donante. Se dan, para este supuesto, dos posibles situaciones:

La primera, cuando lo lleve a cabo merced al consentimiento del varón con el que conviva. En esta situación, la filiación será atribuida al hombre que consienta previamente dicha fecundación no natural de la persona con la que mantiene una relación con semen de otra persona que dona. Como requisito previo, será necesario que haya plasmado la autorización escrita, cumplimentado en la institución autorizada y antes de que las prácticas de fecundación se hayan iniciado (artículo 8.2 LTRHA). Además, será necesario acudir a los títulos de definición del nexo filial no derivado del matrimonio, amparado por el precepto $120 \mathrm{CC}$.

La segunda, en caso de que la mujer soltera acuda a estos métodos reproductivos mediante la colaboración de un donante, el nacido sólo dispondrá de filiación materna y no paterna, puesto que al donante en ningún caso se le atribuirá el vínculo filial.

\section{Conclusiones}

Como hemos podido ver a lo largo del presente estudio, la permanente evolución científica comporta sistemáticamente un desafío para el mundo jurídico y bioético, así como en relación a los efectos que ello imprime en los Derechos Humanos, como, en lo que aquí interesa, el derecho que tiene todo individuo a la vida, la libertad y a la asistencia médica. En este contexto, una de las figuras que más ha evolucionado en 
los últimos años y que más interés ha despertado en la población es la reproducción humana asistida, objeto de análisis.

Fruto de lo anterior, surge la LTRHA, que persigue aceptar el uso de las prácticas de reproducción asistida ante situaciones de infertilidad o para prevenir y tratar problemas cuya razón de ser residía en aspectos genéticos o hereditarios, además de posibilitar que las mujeres, a título individual, pudieran acceder a estas prácticas, al significar que toda mujer podrá ser receptora o usuaria de las técnicas reguladas en la presente ley. La LTRHA no modifica sustancialmente las propuestas contenidas en la normativa precedente, aunque introduce novedades importantes en cuanto a la delimitación de la denominación de preembrión, la prohibición de la clonación en seres humanos que busquen funciones reproductivas, la regulación de novedosas técnicas reproductoras asistidas, la ampliación del campo de acción al diagnóstico genético preimplantacional que posibilita nuevos caminos en la prevención de enfermedades de carácter hereditario, el fortalecimiento de las anotaciones y otros procedimientos informativos que contribuyan a un más amplio asesoramiento a los usuarios que acudan a esta clase de prácticas, o la supresión de las disparidades en lo referente al futuro de los embriones en fase previa que estuvieran crioconservados, además de eliminar las limitaciones que se habían instaurado en la regulación anterior para la generación de ovocitos.

Por último, en cuanto a la fijación de la identidad, se ha puesto de relieve las distintas modalidades existentes y las notas definitorias existentes en cada una de ellas, dependiendo de si es homóloga (dentro del matrimonio y con el consentimiento de ambos progenitores) o heteróloga (en que la persona es fecundada mediante esperma de un donante, ya sea dentro del matrimonio o fuera de él), analizándose la disparidad de supuestos y, por ende, de efectos jurídicos previstos en la norma atendiendo a cada caso.

\section{Referencias bibliográficas}

ALBERT, Marta María (2018): “¿Hacia un derecho universal? Bioderecho en acción y funcionalización del valor de la vida humana”. En Cuadernos de Bioética, No 81, pp. 223-238.

ALONSO, Nieves (2020): "La maternidad subrogada en el constitucionalismo europeo: dificultades para su anclaje legal ante una realidad social en constante evolución”. En Unión Europea Aranzadi, No 1, pp. 17-45.

APARISI, Ángela (2019): "Al principio de la dignidad humana como fundamento de un Bioderecho global". En Cuadernos de Bioética, No 81, PP. 201-222. 
CASADO, María (2018): "Bioética y Derechos Humanos: sobre la bioética como herramienta para la Democracia”. En IUS ET VERITAS: Revista de la Asociación IUS ET VERITAS, № 53 , pp. 172-180.

CRAVIOTTO, Patricia (2019): "Embriones en reproducción humana asistida: Contro-versias sobre la congelación y el estudio genético pre-implantatorio". En Revista electrónica de Derecho y Ciencia, № 1, pp. 54-89.

DANILUK, Judith y KOERT, Emily (2017): “Childless Canadian men's and women's childbearing intentions, attitudes towards and willingness to use assisted human reproduction. En Human Reproduction, No 8, pp. 2045-2412.

DÍAZ, Javier (2019): "La gestación por sustitución ante el Registro Civil español. Evolución de la doctrina de la DGRN y de la jurisprudencia española y europea”. En Revista de Derecho Civil, № 1, pp. 53-131.

DUPLÁ, Antonio (2019): "El presente del pasado: el principio mater semper certa est y su reflejo en la actual legislación sobre reproducción humana asistida”. En Revista Internacional de Derecho Romano, No 22, pp. 289-325.

LEMMENS, Trudo y FLAVELLE, Andrew (2017): Regulatin creation: the law, ethics, and policy of assisted human reproduction (Londres, University of Toronto Press).

LLEDÓ, Francisco (2017): "La Ley sobre las técnicas de reproducción humana asistida”. En LLEDÓ, Francisco. Las relaciones paterno-filiales, adopción y potestad parental (Madrid, Dykinson). pp. 75-88

MARTÍN, Marisa (2019): "La supuesta donación de la capacidad reproductiva en la gestación por sustitución”. En Derecho y salud, No 1, pp. 169-179.

PARDO, María José (2019): “El derecho a conocer el origen biológico de los hijos versus el derecho al anonimato en caso de utilización de técnicas de reproducción humana asistida heterólogas". En Familia y sucesiones: cuaderno jurídico, № 127 , pp. 17-20.

RABADÁN-SÁNCHEZ, Fuensanta (2019): "El derecho a conocer los orígenes biológicos de la reproducción asistida". En Actualidad jurídica iberoamericana, № 10, pp. 586-613.

ROMERO, Carlos María (2017): "El Bioderecho y la Bioética, un largo camino en común". En Revista Iberoamericana de Bioética, № 3, pp. 13-45.

VALDÉS, Erick (2019). "Bioderecho, daño genético y derechos humanos de cuarta generación”. En Boletín de Derecho Comparado, № 144, pp. 1197-1228.

VIDAL, Jaime (2019): "Acerca de la regulación jurídica de las técnicas de reproducción humana asistida". En Actualidad jurídica iberoamericana, № 10, pp. 478-513. 